Как цитировать статью: Карсунцева О. В. Российское машиностроение: курс на импортозамещение // Актуальные проблемы экономики и права. 2016. № 1. С. 48-61.

\title{
О. В. КАРСУНЦЕВА ${ }^{1}$ \\ ${ }^{1}$ Самарский государственный технический университет, г. Самара, Россия
}

\section{РОССИЙСКОЕ МАШИНОСТРОЕНИЕ: КУРСАА ИМПОРТОЗАМЕЩЕНИЕ}

Цель: выявление особенностей и приоритетных направлений повышения әффективности использоваиия и развития производственного потенциала отечественных предприятий машиносроения в ґамках реализации программы по импортозамещению в промышленности РФ.

Методы: междисциплинарный характер проблемы повьшения уровня испподзования производственного қотеншиала машиностроительного производства предопределил применение метододогического инструментария включаущего в себя общенаучные методы и приемы - как эмпирически (наблюдение, описание, измерение), хак и теоретические (анализ, синтез, индукция, дедукция, формализация, моделирование, обобщение, сис емный подход, вероятностные методы).

Результаты: на основе проведенного анализа сдатистичесқих данных о состюянии производственного потенциала машиностроительного комплекса РФавтором установлеио, что в российскои экономике присуғствуют необходимые условия и возможности для решения прфблемы компиексной модернизации и обеспечения темпов опережающего развития предприятий отечественного мажинострөения. Обосновано, что фундаментыо для реализации этих целей должна стать эффективная (комтлексная) гофударственная программа импортозамен(ения, соответствующая современным условиям и способная обеспечить иелостность и многоаспектность пропесса трансформаций.

Научная значимость: определена система целевых приоритетов и ориентиров комплексной государственной программы импортфзамещения в мапиностроении на период до 2025 г., собтветствующая современным условиям и способная обеспечить шелостносиь и многоаспектность процесса трансформаций в рамках государственно-частного партиерства с целью оеуществления страте ического маневра, ориентированного на переход отечественного машиностроительного комплекса в опережающем темпе-на путу интенсивного развития согласно потребностям растущей экономики и национальной безопасности государства.

Практическая значиуость: разработаниая система прақтических рекомендаций может быть использована органами ғосударственной власти при разработке программ инновационного развития машиностроительного комплекса РФ. Ключевые слова: экономика и управление нароциым хозяйством; машиностроение; государственная программа, импортозамещение; пропраммно-целевые меходы; программный период; технологии; государственно-частное партнерство; инвестиции.

Введение

Смещение пропорџий объемяв бюджетных ассигнований и инвестищионных средств в сторону сырьевого сектора экономики привело к замедлению темпов роста обрабатывающей промышленности в целом и отечественного машиностроения в частности. Неустойчивое финансовое состояние предприятий машиностроительного комплекса является следствием распада материально-технической базы, разрыва межотраслевых и межхозяйственных связей, что свидетельствует об отсутствии адекватного хозяйственного механизма, эффективных методов и инструментов государственного регулирования.
С учетом необходимости усиления государственного внимания к поддержке наиболее значимых видов экономической деятельности с точки зрения их социально-экономического и бюджетного вклада в экономику целесообразно в качестве приоритетной сферы государственного регулирования как на федеральном, так и региональном уровне рассматривать именно машиностроительный комплекс. В этой связи следует отметить, что сравнительно недавно произошло изменение курса государственной промышленной политики со смещением его на принципиально новые позиции: на подготовку и проведение стратегических и структурных преобразований в различных областях 
машиностроительного комплекса РФ, что позволило повысить уровень его инвестиционной привлекательности в последние годы ${ }^{1}$. Это мнение подтверждается динамикой реальных инвестиций (в том числе иностранных компаний) в российское машиностроение (рис. 1)2.

Решение системной проблемы активизации процессов импортозамещения, а следовательно, обеспечение опережающего развития российского машиностроения невозможны без формирования системы эффективных стратегических механизмов, позволяющих с помощью качественной диагностики и проектирования компонентов процесса устойчивого развития, а также внедрения обоснованных стратегических рекомендаций создать благоприятную среду для устойчивого бескризисного функционирования машиностроительных предприятий. Есть основания полагать ${ }^{3}$, что в российской экономике присутствуют необходимые условия и возможности для решения проблемы комплексной модернизации и обеспечения темпов опережающего развития отрасли ${ }^{4}$. Фундаментом для реализации этих целей должна стать эффективная (комплексная) государ гвенная программа импортозамещения, соответствуг щая современным условиям и способная обеспечить ц лостность и многоаспектность процесса трансформс ций.

Формирование комплексной государственной программы импортозаме я в машиностроении обусловлено требованием вре кени бхддимыми условиями стратегич ого план рованџ в машиностроении, отраженнымы системс реализации Концепциилолгосроу го сош ан, о-эко бмического разг пाия Ро чи до 2020 вержде ой распоряжение мавительс

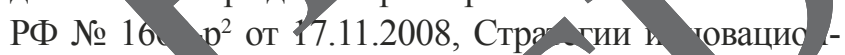
Рг развити Ф на период до 2020 г утве тен лой

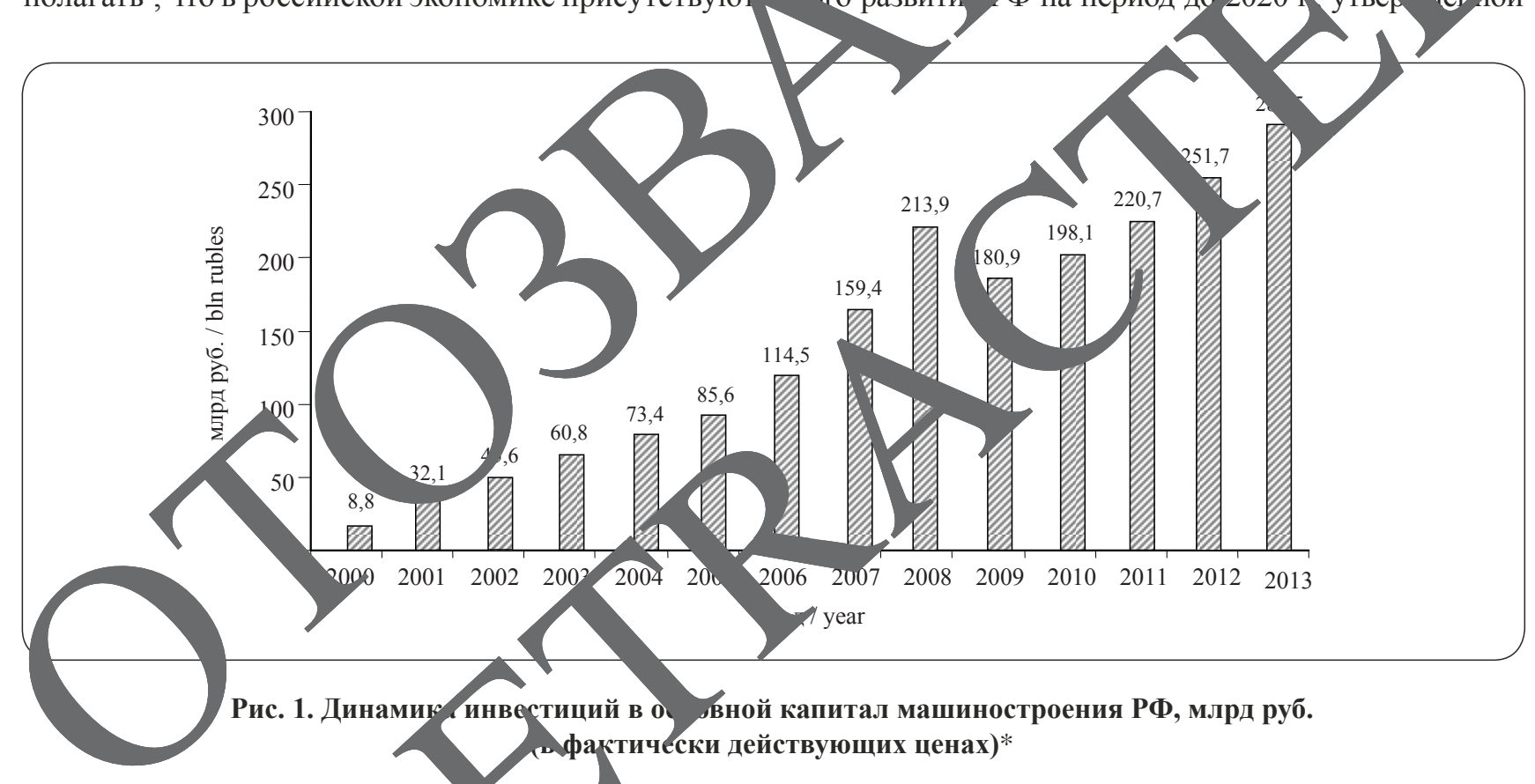

* Составлено автором по даннық Федерал сой службы государственной статистики. URL: http://www.gks.ru/wps/wcm/ connect/rosstat_main/rossat/ru/ tistics/e_op ydevelopment/ (дата обращения: 14.03.15).

Fig. 1. Dynamics of

* Compiled by the author the data of Federal Agency of State Statistics, available at: http:/www.gks.ru/wps/wcm/connect/rosstat_ main/rosstat/ru/statistics/econom, evelopment/ (accessed date: 14.03.15).

1 Путин В. В. Послание Президента Федеральному Собранию // Вестник Российской нации. 2015. Т. 1. № 1-1 (39). С. 8-16.

2 Росстат. Центральная база статистических данных. URL: http:// www.gks.ru/dbscripts/Cbsd/DBInet.cgi\#1 (дата обращения: 12.01.16).

3 Путин В. В. Послание Президента Федеральному Собранию // Вестник Российской нации. 2015. Т. 1. № 1-1 (39). С. 8-16.

${ }^{4}$ Концепция долгосрочного социально-экономического развития Российской Федерации на период до 2020 года: распоряжение Правительства РФ № 1662-р от 17.11.2008. 
распоряжением Правительства РФ № 2227- p $^{5}$ от 08.12.2011 и Государственной программе РФ «Развитие промышленности и повышение ее конкурентоспособности на период до 2020 года» ${ }^{6}$. Основной упор в разработке программы должен быть сделан на максимальном учете новых тенденций в развитии мирового машиностроения, выражающихся, к примеру, в появлении новых производственных технологий и других вызовов времени.

\section{Результаты исследования}

Машиностроительный комплекс должен стать объектом государственной поддержки в совокупности всех видов экономической деятельности, входящих в него. Однако по причине отсутствия в настоящее время возможности финансовой поддержки абсолютно всех подотраслей комплекса целесообразно выбрать только приоритетные направления, учитывая роль и значение того или иного промышленного сектора в обеспече нии инновационного развития экономики страны [1] В связи с этим выделим сферы машиноетроительиого производства по мере убывания конкурентоспособности и наукоемкости ироизводимой продукции [2]:

1. Производства, использующие поколение технологий, близких к пятому технологическому укладу: авиационная и ракетно-космическая промышленность, атомное машиностроение, электроника и микроэлектроника, наукоемкое приборостроение, прөмышленность средств связи и телекоммуникаций, а также прочие сферь промышленног производства, предопределяющие на современном этапе темпы развития высоких технологий. Преимуществейно эти производства относятся к категории экспюртоориентированных и требуют повьшенного внимания и различных форм поддержки со сторонь государства (например, реализации государственной научнотехнической политики, төсударственных целевых программ развития, создания государственных инновационных центров и свободных экономических зон, льготной налоговой, кредитной политики и др.).

\footnotetext{
5 Стратегия инновационного развития Российской Федерации на период до 2020 г.: утв. распоряжением Правительства РФ № 2227-р от 08.12.2011.

${ }^{6}$ Об утверждении Государственной программы РФ «Развитие промышленности и повышение ее конкурентоспособности на период до 2020 г.»: Постановление Правительства РФ № 328 от 15.04.2014. URL: http://base.garant.ru/70643464 (дата обращения: 16.07.15).
}

2. Производства, использующие технологии четвертого технологического укладя:

а) имеющие высокий производственный потенциал для перспективного развития и совершенствования основных результатов производственно-хозяйственной деятельности в рамках существующего уклада. В отечественном машиностроении к таким производствам традиционно относятся энергетическое, нефтехимическе машиностроение автомобилестроение, судостроение, железнодорожное машиностроение, стапкостроеиие, приборостроение и другие сферы промьшиенного производства. Здесь юсударственная поддержка может заключаться в иепфльзовании рычаТов финансово-экономического и институционального регулирования и зависеть огвыбраниьк приоритетов иаучн-технического развитяя;

б) уже сформировавпиеся сферы отечественного проуьшленного производства, ориентированные на импортозамещение: ороительно-дорожное и коммунальное машиностроение, сельскохозяйственное машиностроение, машиностроение дلя легкой, пищевой промышленности, торговли и т. А. В зависимости от состояния рыночнюй конъюнктуры государственная поддержка этих чроизводств,может быть направлена на индивидуальное совершенствование сугубо улучшающего порядка (повыпение качества продукции, развитие системы продвижения товаров на рынки и пр.) и не требовать маештабных капитальных вложений, а также политики чрезвычайного государственного вмешательства [2].

3. Производства, использующие технологии четвертого технологического уклада, выпускающие преимущественно несложную продукцию, которая имеет стабильный спрос на рынке.

Для обеспечения стратегического маневра в области развития российского машиностроения необходимы комплексная модернизация материально-технической базы и опережающее развитие производств, отнесенных к первым двум уровням по важности и приоритетности государственной поддержки. Обосновать целесообразность такого выбора можно тем, что скорость распространения новых технологических укладов во всех сферах экономики, а следовательно, создание и реализация возможностей производства современного ресурсосберегающего высокопроизводительного оборудования зависят непосредственно от уровня развития и интенсификации наукоемких и высокотехнологичных производств $[3,4]$. 
В направлении разработки стратегии развития машиностроения РФ уже предприняты определенные действия. Начиная с 2008 г. были разработаны и реализуются в настоящее время ряд стратегий развития отдельных направлений машиностроительного производства, в том числе авиационного, судостроительного, автомобильного, электронной промышленности, энергомашиностроения, транспортного, сельскохозяйственного, строительно-дорожного и коммунального машиностроения. Однако, несмотря на предпринятые попытки в этом направлении, говорить о существовании в России государственного комплексного стратегического подхода к модернизации машиностроения пока не приходится. Во-первых, некоторые из упомянутых документов рассчитаны только на период до 2015 г., во-вторых, они не в полной мере соответствуют принципу системности из-за недостаточной согласованности как между собой, так и с общегосударственными задачами перспективного социально-экономического развития. В табл. 1 отражены фактически достигнутые результаты реализации целевых сценариев развигия отечественноге машиностроения [2].

Анализ промежуточных показателей табл 1 фвидетельствует о низкой эффективности уже разработанных и принятых к реализации в настояшее время стратегий развития ключевых направлений машиностроительного производства ${ }^{7}$ Фактически полученные показатели значительно отстают от запланированных по всем видам экономической деятельности в машиностроении [2] Самый большой разрыв продемонстрировали подо трасли траңспортного машиностроения В 2012-2013 гг, в частности, железнодорожное и подъемно-транспортноемашиностроение, судостроеиие, автомобилестроение, которье на протяжении предшествующи трех лет являлись главными локомотивами роста не только всего машиностроительного комплекса страны, но и обрабатывающей промышленности в целом.

Основные результаты производственно-хозяйственной деятельности машиностроительных предприятий в последние годь определялись преимущественно быстро сокращающимся внутренним спросом на инвестиционную технику как отечественного

7 Промышленность России: стат. сб. / Федер. служба гос. статистики (Росстат). М., 2006; 2008; 2010; 2014 производства, так и импортного. Именно по этой причине в 2012 г. произошло сокращение производства по таким номенклатурным позициям металлургического машиностроения, как кузнечно-прессовое, сталеплавильное оборудование, машины непрерывного литья заготовок, литейно-прокатные агрегаты, а также сельскохозяйственного машиностроения (зерноуборочные комбайны, тракторы и прочие сельскохозяйственные машины и оборудование) [5].

На фоне снижения инвестиционного спроса сохранялись темпь роста потребительского спроса на бытовую технуку, электроңику, легковые автомобили, что подкреплялось преимушественно потребительским кредитованием со сторены финансовых учреждеңий. Однако к кнцу 2013 к. он также начал ослабевать.

Инвестиционный спрос не актмвизировался и 2013 г., следовательно, динамика производства в еекторах машиностроения, отвечаюших за выпууек оборудования инвестициониого назначения, цродолжает ххудшаться. По прогяозным оценкам [4], ожидается сиижение потребитешьского спроса, хбтя в этом случае многое будет зависегь от того, какуюо политику выберут банки на рынке потребительского кредитования.

В сложившихся условиях необходимо осуществление стратегического маневра, ориентированного на переходотечественной машиностроительной промышленности в опережающем темпе на путь интенсивного развития, что корождает необходимость решения всего комплекса проблем, накопившихся в законодательной, финансовой, социально-экономической, научно-технической, кадровой и других сферах [5]. При этом временной фактор будет иметь решающее значение, например в развитых странах перевооружение промышленности происходит в среднем каждые 8-10 лет [6]. В данном аспекте разработка программы модернизации российского машиностроения представляется целесообразной через формирование в рамках государственно-частного партнерства комплексной государственной программы импортозамещения в машиностроении.

Потребность в использовании программно-целевых методов определена следующими факторами:

- государственным значением проблемы обеспечения интенсивного и опережающего развития отечественного машиностроения;

- существованием острой необходимости решения рассматриваемой проблемы системными стратегическими методами в рамках единого замысла; 
Экономика и управление народным хозяйством Economics and national economy management

Таблица 1

Динамика плановых и фактически полученных показателей целевого развития машиностроения РФ (в млн руб.)*

Table 1. Dynamics of the actual indicators of the target development of the Russian machine building (million rubles)*

\begin{tabular}{|c|c|c|c|c|c|c|c|c|c|c|c|c|}
\hline \multirow{2}{*}{$\begin{array}{l}\text { Показатель / } \\
\text { Indicator }\end{array}$} & \multicolumn{3}{|c|}{2010} & \multicolumn{3}{|c|}{2011} & \multicolumn{3}{|c|}{2012} & \multicolumn{3}{|c|}{2013} \\
\hline & $\begin{array}{l}\text { план / } \\
\text { planned }\end{array}$ & $\begin{array}{l}\text { факт / } \\
\text { actual }\end{array}$ & $\begin{array}{c}\text { отклонение, \% / } \\
\text { declination }\end{array}$ & $\begin{array}{l}\text { план / } \\
\text { planned }\end{array}$ & $\begin{array}{l}\text { факт / } \\
\text { actual }\end{array}$ & $\begin{array}{c}\text { отклонение, \% / } \\
\text { declination }\end{array} \mid$ & $\begin{array}{c}\text { план / } \\
\text { planned }\end{array}$ & $\begin{array}{l}\text { факт / } \\
\text { actual }\end{array}$ & $\begin{array}{c}\text { отклонение, \% / } \\
\text { declination }\end{array} \mid$ & $\begin{array}{l}\text { план / } \\
\text { planned }\end{array}$ & $\begin{array}{l}\text { факт / } \\
\text { actual }\end{array}$ & $\begin{array}{c}\text { отклонение, \% / } \\
\text { declination }\end{array}$ \\
\hline \multicolumn{13}{|c|}{ Нефтебуровое оборудование / Oil-extracting equipment } \\
\hline $\begin{array}{l}\text { Российский рынок / } \\
\text { Russian market }\end{array}$ & 45088 & 44987 & $-0,24$ & 46632 & 44306 & $-4,99$ & 47559 & 49570 & & & 50706 & 5,25 \\
\hline $\begin{array}{l}\text { Всего произведено } \\
\text { в Pocсии / Produced } \\
\text { in Russia }\end{array}$ & 16733 & 14656 & $-12,41$ & 18291 & 15104 & $-17,42$ & & & & 20788 & 18312 & $-11,91$ \\
\hline $\begin{array}{l}\text { в том числе: } \\
\text { на внутренний рынок / } \\
\text { including for the internal } \\
\text { market }\end{array}$ & 15644 & 13699 & $-12,43$ & 16894 & 14052 & & & & & & & $-10,22$ \\
\hline экспорт / export & 1089 & 957 & $-12,12$ & 1397 & 1052 & & & 264 & $-25,87$ & & 318 & \\
\hline Импорт / Import & 29444 & 31288 & 6,26 & 29739 & 30254 & & 02 & 32857 & 11,00 & 49 & 2 & 15,26 \\
\hline $\begin{array}{l}\text { Доля импорта, \% / } \\
\text { Import share, \% }\end{array}$ & 65,3 & 69,5 & 6,43 & & & & & 66,3 & & & 66,5 & 9,56 \\
\hline $\begin{array}{l}\text { Pocсийский рынок / } \\
\text { Russian market }\end{array}$ & 10800 & 6462 & & & & & 11498 & & & 11647 & 6476 & $-44,40$ \\
\hline $\begin{array}{l}\text { Всего произведено } \\
\text { в Pocсии / Produced } \\
\text { in Russia }\end{array}$ & 9625 & 5448 & & & & $-51,49$ & 11801 & 5704 & $-51,67$ & 2588 & 5877 & $-53,31$ \\
\hline $\begin{array}{l}\text { в том числе: } \\
\text { на внутренний рынок / } \\
\text { including for the internal } \\
\text { market }\end{array}$ & 5737 & & & & 996 & $-83,4$ & 6221 & & 03 & 6388 & 1159 & $-81,86$ \\
\hline экспорт / export & & 054 & 4,2 & 4658 & 4182 & $-10,22$ & 5 & 4275 & $-23,39$ & 6200 & 4718 & $-23,90$ \\
\hline Импорт / Import & 5183 & & & 5257 & 4956 & $-5,73$ & 5277 & 5266 & $-0,21$ & 5260 & 5317 & 1,08 \\
\hline $\begin{array}{l}\text { Доля импорта, \% } \\
\text { Import share, \% }\end{array}$ & & & & 46,6 & & 8,76 & 45,9 & 78,6 & 71,24 & 45,2 & 82,1 & 81,63 \\
\hline $\begin{array}{l}\text { Российский рь } \\
\text { Russian market }\end{array}$ & & & $-5,90$ & & & & 77205 & 70203 & $-9,07$ & 78208 & 77006 & $-1,54$ \\
\hline $\begin{array}{l}\text { в Pocсии / Produced } \\
\text { in Russia }\end{array}$ & 20561 & 19742 & & & & $-14,93$ & 24298 & 21955 & $-9,64$ & 22936 & 21937 & $-4,36$ \\
\hline $\begin{array}{l}\text { на вмутренний риток / } \\
\text { including for the internal } \\
\text { market }\end{array}$ & 16350 & & & 17837 & 14666 & $-17,78$ & 18851 & 16971 & $-9,97$ & 16822 & 16473 & $-2,07$ \\
\hline экспорт / export & 4211 & & $-5,7$ & 4708 & 4512 & $-4,16$ & 5447 & 4984 & $-8,50$ & 6114 & 5464 & $-10,63$ \\
\hline Импорт / Import & 634 & 5310 & 0,90 & 53156 & 54867 & 3,22 & 52907 & 53232 & 0,61 & 55272 & 60533 & 9,51 \\
\hline $\begin{array}{l}\text { Доля импорта, \% / } \\
\text { Import share, \% }\end{array}$ & 71,9 & & & 70,2 & 78,9 & 12,39 & 68,5 & 75,8 & 10,66 & 70,7 & 78,6 & 11,17 \\
\hline \multicolumn{13}{|c|}{ Горное оборудование / Mining equipment } \\
\hline $\begin{array}{l}\text { Российский рынок / } \\
\text { Russian market }\end{array}$ & 17342 & 15159 & $-12,59$ & 17935 & 15852 & $-11,61$ & 18291 & 16004 & $-12,50$ & 18529 & 15831 & $-14,56$ \\
\hline $\begin{array}{l}\text { Всего произведено } \\
\text { в Pocсии / Produced } \\
\text { in Russia }\end{array}$ & 12892 & 10507 & $-18,50$ & 13547 & 10982 & $-18,93$ & 14058 & 11304 & $-19,59$ & 14501 & 11629 & $-19,81$ \\
\hline $\begin{array}{l}\text { в том числе: } \\
\text { на внутренний рынок / } \\
\text { including for the internal } \\
\text { market }\end{array}$ & 10870 & 8719 & $-19,79$ & 11374 & 9178 & $-19,31$ & 11733 & 9507 & $-18,97$ & 12021 & 9514 & $-20,86$ \\
\hline экспорт / export & 2022 & 1788 & $-11,57$ & 2174 & 1804 & $-17,02$ & 2325 & 1797 & $-22,71$ & 2480 & 2115 & $-14,72$ \\
\hline Импорт / Import & 6471 & 6440 & $-0,48$ & 6562 & 6674 & 1,71 & 6558 & 6497 & $-0,93$ & 6508 & 6317 & $-2,93$ \\
\hline $\begin{array}{l}\text { Доля импорта, \% / } \\
\text { Import share, \% }\end{array}$ & 37,3 & 42,5 & 13,94 & 36,6 & 42,1 & 15,03 & 35,9 & 40,6 & 13,09 & 35,1 & 39,9 & 13,68 \\
\hline
\end{tabular}

Карсунцева О. В. Российское машиностроение: курс на импортозамещение /

Karsuntseva O. V. Russian machine-building: course to import substitution 
Продолжение табл. 1 / Continued Table 1

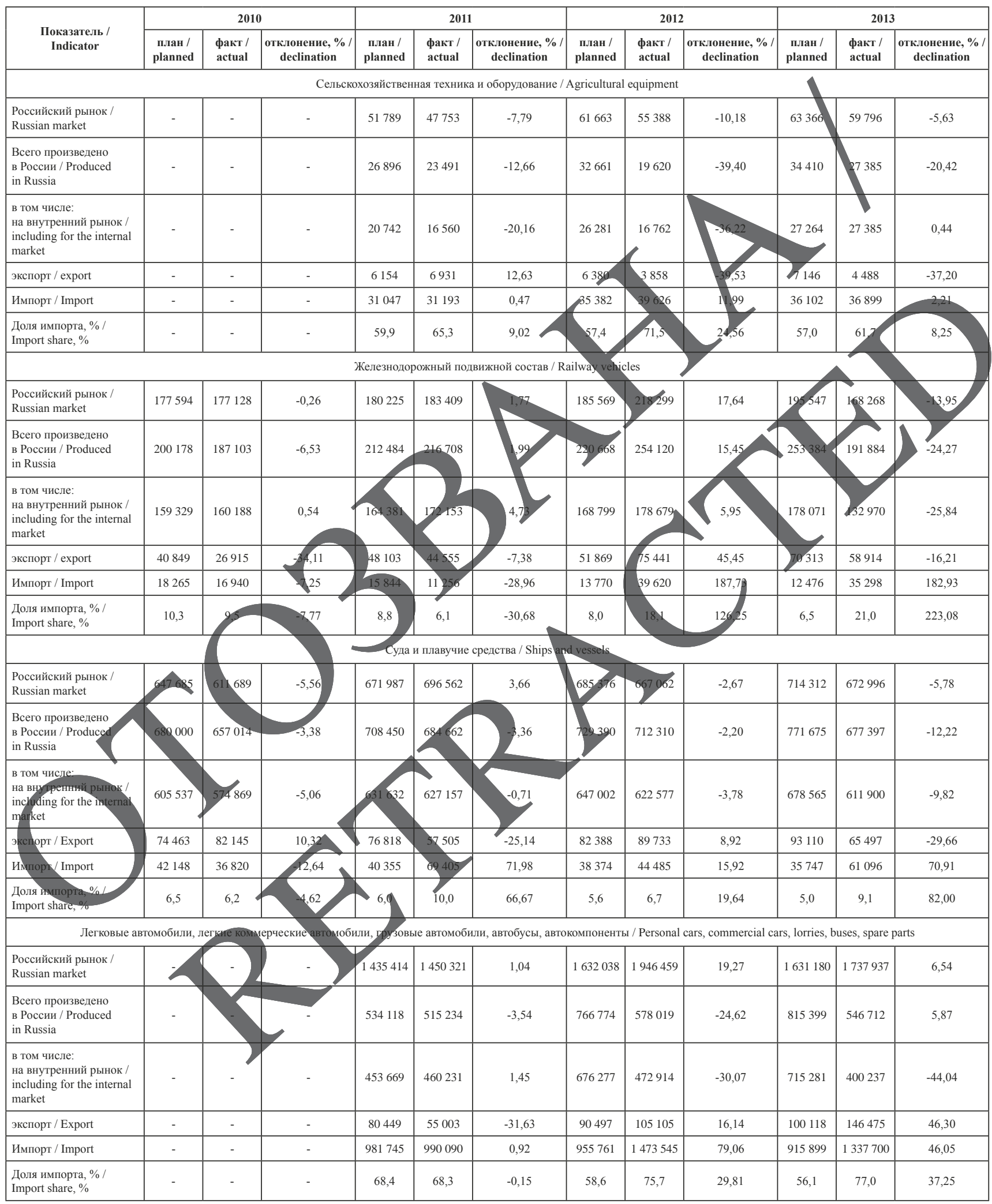


Окончание табл. 1 / The end Table 1

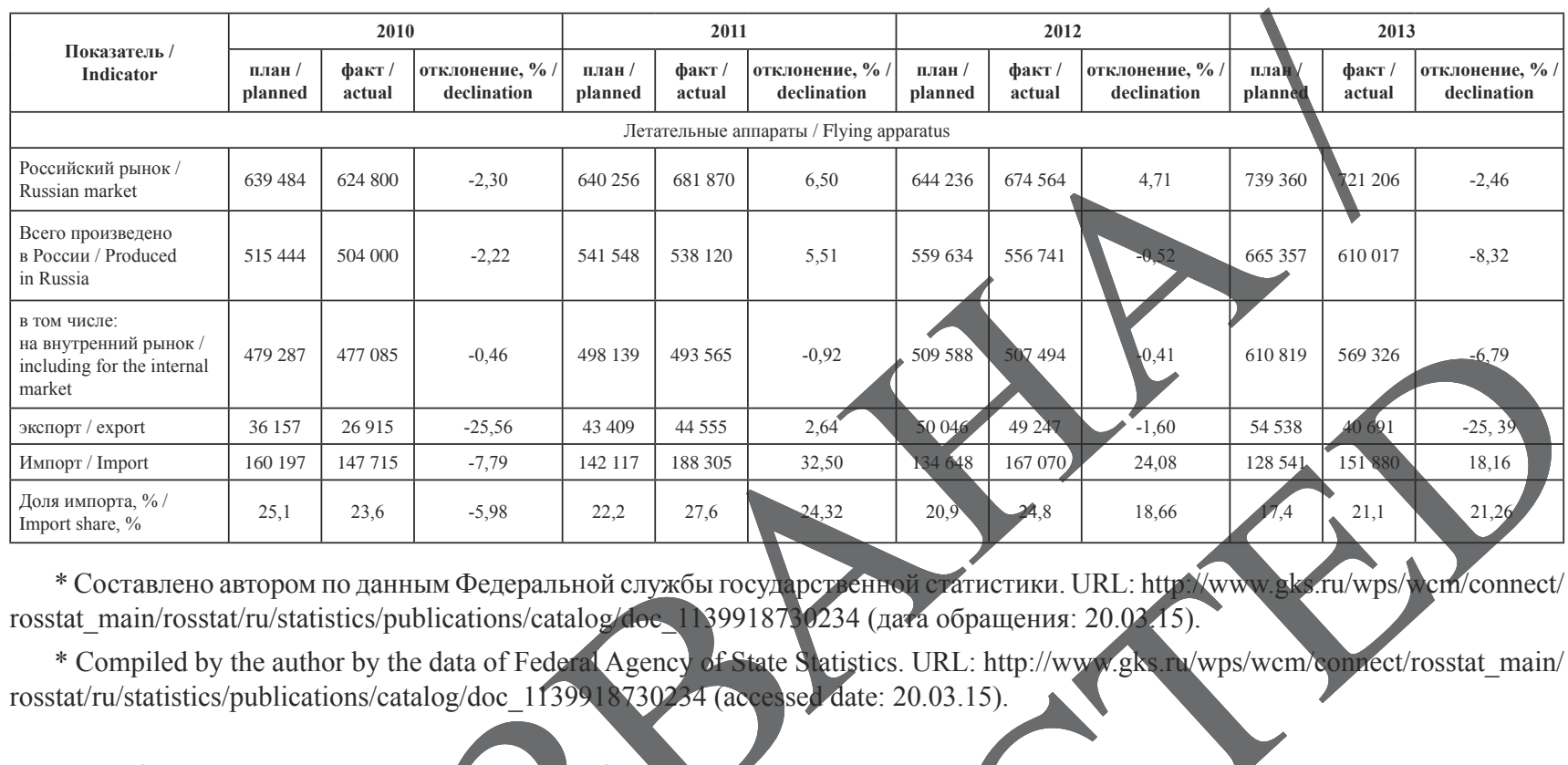

- необходимостью оперативной разработки ипринятия мер, направленных на совершенствование законодательства РФ в сфере промышленной, таможеннотарифной, фискальной, социальной, образовательной политики с учетом временного аспекта;

- сложностио с учетом многоуровневого характера проблемы ипереплетения государственных интересов с частными;

- получением социально-экономического эффекта. Все вышеперечисленные факторы етановятся дополнительным стимулом в вопросах консолидации усилий государства и бизнеса, направленных на формирование комплексной государственной программы импортозамещения и обеспєчения опережающего развития российского мапиностроения. Программа должна содержать комплекс стратегических инициатив развития производственного потенциала предприятий отечественного машиностроения; в ней должны быть сформулированы цели и задачи обеспечения выпуска конкурентоспособной наукоемкой продукции, модернизации машиностроительного комплекса.

Комплексная программа импортозамещения должна исходить не из адаптации машиностроения к условиям внешней среды, а из системы целевых установок перспективного развития, включающей в себя устойчивый (инвариантный) комплекс целевых индикаторов, характеризующих уровень такого развития. Кроме того, государственная программа не должна рас- сматриваться только как определенная совокупность конкретных проектов, технологий, объемов требуемых инвестиционных ресурсов, уровня господдержки. Такой подход искажает сущность программы как документа [7]. Работающей считается такая программа, после тринятия которой нельзя действовать так, как будто ее не существует $[8,9]$. Понимание этого является неббходимым условием активизации процессов импортозамещения в машиностроительном комплексе уменно сегодня и именно в условиях обострения геополитических противоречий и новых угроз глобализации.

Целевое видение комплексной государственной программы импортозамещения в машиностроении предопределяется вызовами и угрозами внутренней и внешней среды предстоящего долгосрочного периода, а также совокупностью важнейших целей и задач системы стратегического управления. Необходимость адекватной реакции на предстоящие внешние и внутренние вызовы и угрозы, а также необходимость оперативного решения уже существующих проблем в машиностроительном комплексе создают пространство стратегических целей и задач новой государственной программы.

Стратегической целью устойчивого развития России в обозримом будущем является превращение ее в высокоразвитую экономическую державу, фундаментом которой служит постиндустриальная материально-техническая база. Исходя из этого, генеральной 
целью комплексной государственной программы импортозамещения в машиностроении должно стать определение приоритетных направлений, условий и методологии развития отрасли на среднесрочную и долгосрочную перспективу в целях обеспечения ее опережающего развития, высокой инновационной активности, социально-экономической эффективности и конкурентоспособности в рамках соответствия потребностям растущей экономики Российской Федерации, а также внешнеэкономическим интересам с ориентацией на национальную безопасность [2].

Достижение генеральной цели программы становится возможным при выполнении следующих условий:

- формирование благоприятной среды для обеспечения устойчивого социально-экономического развития отечественного машиностроительного комплекса снижение совокупных экономических издержек в сфере производства и эксплуатации машинотехнической продукции, повышение конкурентоспособности российской экономики и обеспечение лидирующих позиций РФ в мировой экономике за счет интенсив ного и опережающего развития машиностроеиия в сочетании с высокими темпами нновационного развития других видов кономической деятельности;

- сосредоточение производственнөп-потенциала машиностроительньх предприятий, научно-исследовательских проектно-конструкторских, технологических организаций машиностроения, а хакже научных центров, хчебных заведений на приоритетных направлениях компдексного решения проблемы онределение целевы задач, сроков, необходимого ббъема ресурсов в существующих и разрабатываемых проектах социально-экономического, научно-техиическою, ореанизационного, нормативно-правового характера в рамках единой программы;

- создание конкурентоспособного современного облика отечествеиного маииностроения на основе повышения уровня испољзованияи инновационного развития производственного потенциала, совершенствования законодательной и нормативно-правовой базы в рамках наиболее полного удовлетворения потребностей государства и частного сектора в современном высокотехнологичном оборудовании [2]. Отличительной чертой реализации программ и проектов такого рода также является их ориентация на получение долгосрочного социального эффекта как следствие инвестирования в развитие человеческого потенциала [10].

Для решения намеченных стратегических задач целесообразно выделить два программных периода: средний (2017-2021 гг.) и дальићй (2021-2025 гг.). Выбранный интервал реализации Мрограммы является целесообразным, поскольку сов адает со средней продолжительностью осуществления действующих в настоящее время нрограмм (стратегй) стратегического развития различныхподотраслей машиностроения. К примеру, до 2020\%. являюется действующими Стратегия развития энергомашиностроения $\mathrm{P}^{8}$, Стратегия развития тяжелого машиностроения $Р \Phi^{9}$, Стратегия развития судостроительной иромышленности РФ०, Стратегия развития сельскохозяйственного машиностроения России ${ }^{11}$, Стратегия развития автомобильной промышленности РФ'12. И до 2025 к. Государетвенная программа РФ «Развитие әвиационной иромышленност $Р Ф\rangle^{13}$, Стратегия развития лектронной промышлеңности РФ $\Phi^{14}$, Государственная программа «Развитие электронной и радиоэлектронной промышденности» ${ }^{15}[11]$.

Каждый эгап имеет свои характерные особенности, цель, задачи, критерии и ресурсное обеспечение. 8 Стратегия развития энергомашиностроения Российской Федерации на 2010<2020 гг. и на перспективу до 2030 г.: утв. Приказом Миниетерства промышленности и торговли РФ № 206 от 22.02.2011.

9 Стратегия развития тяжелого машиностроения на период до 2020 г.: утв. Приказом Мин-ва промышленности и торговли РФ № 1150 от 09.12.2010.

${ }^{10}$ Стратегия развития судостроительной промышленности на период до 2020 г. и на дальнейшую перспективу: утв. Приказом Министерства промышленности и энергетики РФ № 354 от 06.09.2007.

${ }^{11}$ Стратегия развития сельскохозяйственного машиностроения России до 2020 г.: утв. Приказом Министерства промышленности и торговли РФ № 1810 от 22.12.2011.

12 Стратегия развития автомобильной промышленности Российской Федерации на период до 2020 г.: утв. Приказом Министерства промышленности и торговли РФ № 319 от 23.04.2010.

${ }^{13}$ Государственная программа «Развитие авиационной промышленности на 2013-2025 гг.»: утв. распоряжением Правительства РФ № 2509-р от 24.12.2012.

${ }^{14}$ Стратегии развития электронной промышленности на период до 2025 г.: Приказ Министерства промышленности и энергетики РФ № 311 от 07.08.2007.

${ }^{15}$ Государственная программа «Развитие электронной и радиоэлектронной промышленности»: утв. распоряжением Правительства РФ № 2396-р от 15.12.2012. 
Основной целью первого этапа является формирование материально-технической, организационно-экономической и правовой базы, способствующей массовому освоению технологий четвертого постиндустриального технологического уклада и последовательному распространению наиболее перспективных технологий пятого и шестого технологических укладов, что потребует опережающих темпов роста машиностроительного производства по сравнению с другими видами экономической деятельности в среднем в 2-3 раза.

На этом этапе необходимы широкомасштабное техническое перевооружение, реконструкция и модернизация производства, создание качественно новой научно-производственной базы машиностроительных предприятий, организация выпуска сложного высокопроизводительного оборудования, в том чиеле мчогофункциональных мобильных комплексов, вовлечение предприятий малого бизнеса в машиностроительный сектор страны для развития сервисной сети техниче ского обслуживания, ремонта, атериально-технияеского снабжения $[12,13]$.

В указанный период должнырешаться оледующие стратегические задачи:

- организация процессов освоения производства новых видов наукоемқой высокотехнологичной продукции, не именщей аналогов па мировом рынке;

- компғексное техническое перевооружение, ре конструкция и модернизация производства;

- существенное расширение сферь сервиса по арантийному и ремонтному обслужфванию,

- формирование благоприятиб условий для сниженияимпортозависимости российской экономики от иностранных производителей машинотехнической продукции и развитие экстортного потенциала.

Ожидаемые результаты эффективной реализации государственной программы импортозамещения в машиностроении представлены на рис. 2.

Основной целью второго этапа должно стать широкое освоение технологий пятого постиндустриального технологического уклада с последовательным распространением наиболее перспективных технологий шестого технологического уклада. За процессами активизации технического перевооружения промышленных предприятий последует существенный рост эффективности производства. Влияние инновационных факторов благоприятно отразится на росте производительности труда и на ресурсосбережении, увеличении показателей рентабельности производственной деятельности [13].

Прогноз развития машиностроительного производства по отдельным видам экономической деятельности в соответствии с целевым сценарием в среднесрочном и долгосрочном периодах представлен в табл. 2.

Темпы обновления оборудовашия рассматриваются как доминирующий иниовационный фактор прогнозирования внугреннего спроса в предстоящем периоде. К основным опраничителям процессов ввода нового оборудоваиия были отнесены: лимиғированные размеры финансирования, неудовлеторительное фбстояние кадрового потенциала, отсу ствие резервов испопьзования производственных мощностей и пр.

Формирование прогиозых коэффициентов обовления оборудования предлагается рассматривать как трехфакторную модель, зависящую от объема инвестируемых средств (I), совөкупности техникотехнологических факторов (E), заданий по выпуску продукции в рамках производственного плана $\left(\mathrm{V}_{j}\right)$ :

прогнозирование показателей выбытия оборудования - каг двухуернную модель:

$$
\mathrm{K}_{\mathrm{B}}=\mathrm{f}\left(\mathrm{F}_{i}, \mathrm{~V}_{j}\right) .
$$

Техиологию формирования прогнозных вариантов можно представить в виде некоторой итерационной ғоследовательности, состоящей из двух этапов. На первом этапе осуществляется выбор величины коэффициента обновления производственного оборудования на основе ретроспективного анализа. Одновременно с этим анализируются показатели использования производственного потенциала.

На втором этапе определяются стоимость нового оборудования и общая величина инвестиционных затрат, включающая в себя предпроизводственные издержки предприятий (монтаж оборудования, пусконаладочные работы и т. д.). Если величина необходимого объема инвестиций выше возможного объема финансирования, то осуществляется повторение (итерация) процедуры прогнозирования при условии понижения исходного значения коэффициента обновления.

В среднесрочной перспективе наиболее высокие темпы развития стоит ожидать в самых успешных сегментах машиностроительного производства в нефтегазовом и энергетическом машиностроении. 
Механизмы осуществления комплексной государственной программы импортозамещения / Mechanisms of the state import substitution program

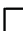

Создание системы благоприятных экономических условий и предпосылок развития машиностроения с помощью совершенствования тарифнотаможенного, налогового, антимонопольного регулирования, осуществления институциональных преобразований / Creating the system of favorable economic conditions and prerequisites of machinebuilding development by improving the customs, taxation, antimonopoly regulation, and carrying out the institutional transformations
Совершенствование государственной системы технического регулирования, включающей в себя перспективные технические регламенты, национальные стандарты и нормы, повышающие управляемость и стимулирующие реализацию важнейших стратегических направлений / Improving the state system of technical regulation, including the prospective technical regulations, national standards and norms, to increase the manageability and stimulating the implementation of the essential strategic directions

Сосредоточение производственного потенциала предприятий, научно-исследовательских, проектно-кенстр, орских, техно, огических организаций машиностроения, а также научных центров, учебных заведений на приоритетных направлениях комплексного решения проблс scientific-research, project-constructive, technological organizations in machine-building, as well as rese th centers and of the complex problem solving

Создание конкурентоспособного современного облика отечественного машиностроения на основс производственного потенциала, совершенствования законодательной и нормативно-правовой базы в ках наиболее олного удовлетворения потребно государства и частного сектора в современном высокотехнологичном оборудовании [14] / Creating the vetitive modern image of the Russian / acrive-build on the basis of the efficient utilization and innovative development of the production pote and private needs in the modern high-tech equipment [14]

\section{(2)}

На макроуровне / At macrolevel

- удовлетворение общенациональных потребностей в широ продукции машиностроения, снижение импортозависимести national demand in the wide range of machine-building production, dependence [16];

- рост доли машиностроения в приросте ВВП/, rowth of in the GDP growth;

- расширение экспорта высокотехнологичной инаукое сонт кци / spanding the export of high-tech and science-consumina nroduction;

- интенсивное развитие произвог лвеннои т тьости в смежн

машиностроению отраслях / int nsive developm fproduction a vity in sectors closely

related to machine-building;

- ликвидация технологическо аазрыва РФ от раз ых стран мира/ eliminating the

technological lagging o Russ Federation from th leveloped countries;

- повышение уро я технологи й безопаснос страны / increasing the level

technological se of of the country;

- укреплен оборо оособности Россииит. д./ Strengthening the defen capability

of Russia, eh
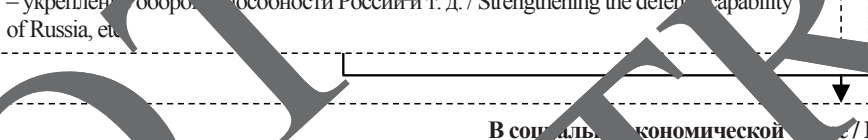

сохранение и а ание новых рабочих мест, предотв цение о са квалифицир занного научно-технического персонала, повышение производительности труда и уровня оплать руда на предприятия / preser ox the existing creating the new working places, preventing the outflow of qualified scientific-technical personnel, increasing the lab productivity and level of pay ent at enterprises

оо дополнительного притока На, export income

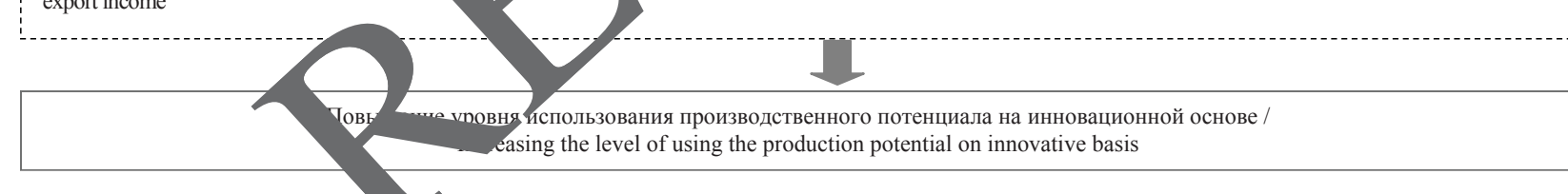

Рис. 2. Основные результаты реализации комплексной государственной программы импортозамещения в машиностроении РФ*

* Источник: составлено автором.

Fig. 2. Main results of implementation of the complex state program of import substitution in the Russian machine-building sector*

* Source: compiled by the author. 
Прогноз развития машиностроительного производства в РФ по видам выпускаемой продукции: целевой сценарий (в \%)*

Table 2. Estimation of machine-building production development in the Russian Federation by the types of production: target scenario $(\%)$ *

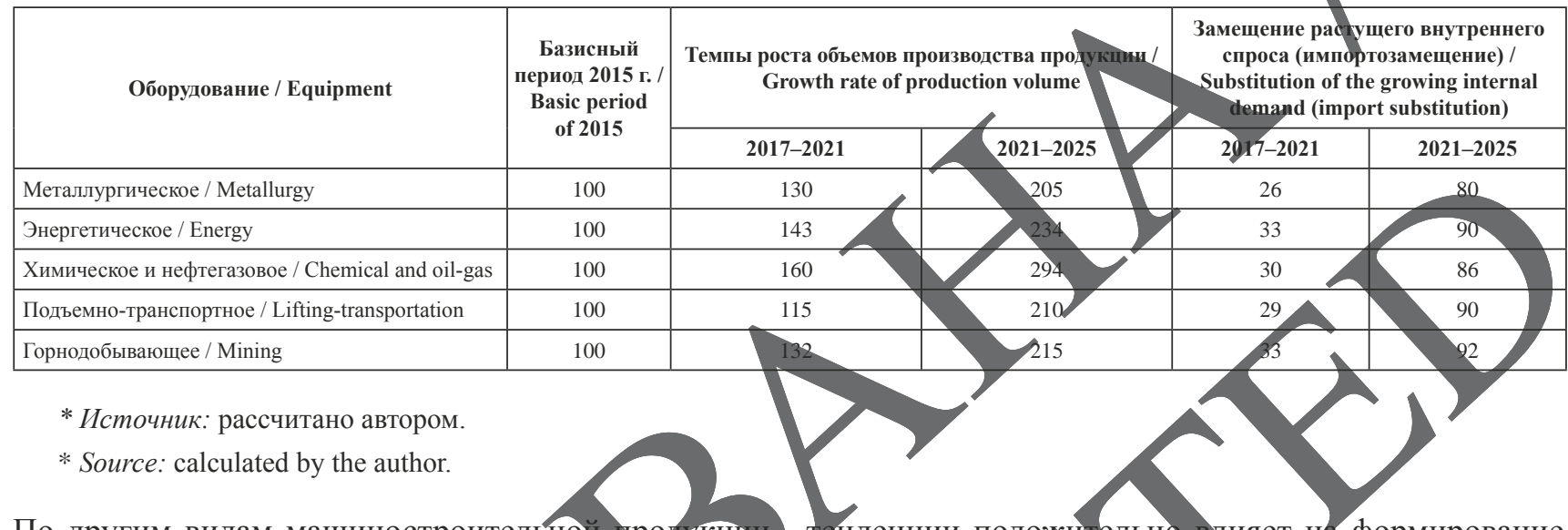

По другим видам машиностроительной продукцик большая доля прироста внутреннего спроса буде обеспечиваться зарубежным оборудованием.

В долгосрочной перспективе три реализации целевого сценария ожидается существенное укрепление конкурентных позиций отечествених производителей не только на внутреннем, но и на внешнем рынке. Интенсивные темпы импортозамещения могут наблюдатьея на рынках подъемно-транспор ного и металлургического оборудования, где в конпедолгосрочного периода дөляимпортируемой техники може стать минимальной.)

Важным резервом роста произвддственного потенциала машиностроения по праву считается мальй и средиий бизнес. В настоящее время успешная реализация инновационных проектов строится на условии распределения рисков между его участниками и широкого использования инетрументов аутсорсинга [17]. В мировой практике наиболее распространена ситуация, когда инициатор проекта может осуществлять лишь сборку, заниматься логистикой и продажей готовых изделий. Основные и вспомогательные производственные операции передаются малому и среднему бизнесу. В отечественной практике преимущественно сохраняется старая система, при которой обрабатываемое изделие проходит все стадии производственного процесса в рамках одного предприятия, т. е. кооперационные связи развиты слабо. Однако с точки зрения рациональной организации производственного процесса учет указанной мировой тенденции положительно влияет на формирование конкурентного облика производителя. Кроме того, важно понимать, что именнопредприятия малого и среднего бизнеса по причине их многочисленности формируют инновационную идеологию общества [6]. Оценивая ситуацию в геополитическом аспекте, можно утверждать, что на нынешнем этапе развития Россия возвращается на мировую арену в статусе сильной и влиятельной державы, с которой необходимо считаться и которая способна реализовать самые масштабные проекты.

Комплексная государственная программа импортозамещения в машиностроении, безусловно, должна быть скоординирована с Концепцией долгосрочного социально-экономического развития России до 2020 г. и с долгосрочным прогнозом развития экономики России до 2030 г., разрабатываемым правительством РФ.

Реализация программы должна обеспечить:

- преодоление технологического отставания российских машиностроительных предприятий от ведущих зарубежных компаний за счет инновационного обновления материально-технической базы отрасли и диверсификации производства;

- активизацию процессов импортозамещения в рамках удовлетворения инвестиционного и потребительского спроса на продукцию отечественного производства;

- рост экспорта машиностроительной продукции; 
- превращение машиностроительного комплекса в уверенно конкурентоспособную отрасль в условиях новой глобальной конкуренции.

Из изложенного вытекают важные следствия. Вопервых, есть все основания полагать, что в России имеются все необходимые возможности для решения задачи модернизации и инновационного развития производственного потенциала машиностроительного комплекса. Во-вторых, в целях эффективного использования имеющегося производственного потенциала возникает острая необходимость формирования реально действующей эффективной государственной политики, отвечающей современным экономическим реалиям и способной обеспечить системность и поливариантность процесса преобразований.

\section{Список литературы}

1. Ершова И. В., Копытов И. В. Государственное регулирование и организационные формы инновационного развития промышленных предприятий // Вопрось управления. 2010. № 11. С. 48-53.

2. Карсунцева О. В. Формирование и реализация стра тегии повышения уровня использованияпроизводственного потенциала предприятий машиностроения; дис.... д-ра экон. наук. Самара, 2015. 362 с.

3. Карсунцева О. В. Пропесс воспроизводствапроизводственного потенциала промышленнюго предприятия // Проблемы экономики именеджмента. 2013. № 1 (17). С. 34-40.

4. Zhabin A. P, Volkodavova E. V., Goryacheva T. V. Multilevel industrial policy: methodologicalbasis of system approach to its formation and implementation // Asian Socia/Science. 2015. No 7. Pp. 176-182.

Карєунцева О. В. Производственный потенциал предприятий машиностроения: оценка, динамика, резервы повышения. М.: ИНФРА-М, 2014. 214 с. 6. Venables A. J. Trade policy, cumulative causation, and industrial development // Journał of Development Economics. 1996. No. 49. Pp. 179-198.

7. Жабин А. П., Грабоздин Ю. П. Роль и значение использования марке иңговых ииструментов в сфере консультационных услуг // Вестник Самарского муниципального института управления. 2014. № 2 (29). С. 42-49.
8. Davenport T. H., Beck J.C. The strategy and structure of firms in the attention economy // Ivey business journal. 2002. No. 4. Рp. 48-53.

9. Грабоздин Ю. П. Организация информационного сопровождения в деятельности консультационных компаний // Экономические науки: теоретический и практический: сб. ст. Междун. науч.-практ. конференции. Уфа: ООО «Аэтерна», 2014. С. 11-14.

10. Татарских Б. Я. Стратегическое развитие промышленных предприятий на инновационной основе // Вектор науки Тольяттинского государственного университета. 2011. № 4. С. $327-3 \not 0$.

11. Карсунцева О. В Организационно-экономическая модель Пповышения эффективности производственно-Хозяйственңой деятельности предприятия // Вектор науки Тольяттинского Государственного университета. 2014. № 1 (27). C. $122-126$.

12. Татарс шения эффективности машиностроительного комплекса россии / Вестник Самарского государственного экономинеского университета. 2013. № 10 (111). С.89-94.

13. Секерин В. Д., Дудин М.Н., Лясников Н. В. Генезис инновационных годходов к стратегическому развитию социально-экономических систем промышленного сектора // Известия Московского государственного технического университета МАМИ. 2014. Т 5. № 4 (22). С. 22-27.

14. Карсунцева О. В. Выявление и использование резервов повынения производственного потенциала предприятия / Интелиект. Инновации. Инвестиции. 2013. № 4. C. $65-70$

15. Кожевникова С. А. Развитие инновационно-инвестиционной деятельности в топливно-энергетическом комплексе: автореф. дис. ... канд. экон. наук. Самара, 2008. 22 с. 16. Карсунцева О. В. Влияние инновационного потенциала на конкурентоспособность промышленного предприятия // РИСК: ресурсы, информация, снабжение, конкуренция. 2009. № 1. С. 113-117.

17. Тойшева О. А., Александрова О. Б. Определение ключевых направлений государственной поддержки малого и среднего предпринимательства в России // Экономика и предпринимательство. 2015. № 3 (56). С. 936-938.

В редакиџию материал поступил 21.01.16

(C) Карсунцева О. В., 2016. Впервые опубликовано в журнале «Актуальные проблемы экономики и права» (http://apel.ieml.ru), 16.02.2016; лицензия Татарского образовательного центра «Таглимат». Статья находится в открытом доступе и распространяется в соответствии с лицензией Creative Commons Attribution License (http://creativecommons.org/licenses/by/2.0/), позволяющей неограниченно использовать, распространять и воспроизводить материал на любом носителе при условии, что оригинальная работа, впервые опубликованная в журнале «Актуальные проблемы экономики и права», процитирована с соблюдением правил цитирования. При цитировании должна быть включена полная библиографическая информация, ссылка на первоначальную публикацию на http://apel.ieml.ru, а также информация об авторском праве и лицензии. 


\section{Информация об авторе}

Карсунцева Ольга Владимировна, доктор экономических наук, доцент, Самарский государственный технический университет

Адрес: 443100, г. Самара, ул. Молодогвардейская, 244, тел.: +7 (8464) 98-60-38

E-mail: olja989@bk.ru

ORCID: http://orcid.org/ 0000-0001-8633-4375

Researcher ID: K-3782-2014 (http://www.researcherid.com)

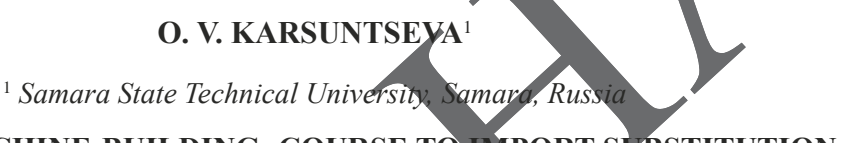

\section{RUSSIAN MACHINE-BUILDING: COURSE TOIMPORT SUBSTITUTION}

Objective: to identify specific priority areas to improve the efficient use and development of the production potential of the Russian machinebuilding enterprises in the framework of the program of import substitution in the Russian industry.

Methods: the interdisciplinary character of the problem of increasing the production potential of machine-building has predetermined the use of methodological tools, including general methods and techniques - both empirical (observation, description, measurement) and theoretical (analysis, synthesis, induction, deduction, formalization, modeling, synthesis, system approach, probabilistic methods).

Results: basing on the conducted analysis of statistical data on the state of the productive capacity of the Russian machine-building complex, the author found that in the Russian economy there are necessary conditions and opportunities to solve the problem of complex modernization and to ensure the pace of rapid development of the domestic machme-burlding enterprises. It is proved that the foundation for these goals' realization should be effective (complex) state program of import substitution, complying with the modern conditions and able to ensure the integrity and the complexity of the transformation process.

Scientific novelty: the system of target priorities was defined, as well as the targets of the complex governmental program of import substitution in the machine-building industry for the period up to 2025, complying with the modern conditions and able to ensure the integrity and the complexity of the transformation process in the framework of public-private parthership for the implementation of the strategic maneuver, aimed at transiting the donestia machine-building complex to the path of intensive development according to the needs of the growing economy and national security

Practical significance: the developed system of practical recommendations can beysed by public authorities in the development of programs of innovative development of engineering complex in the Russian Federation.

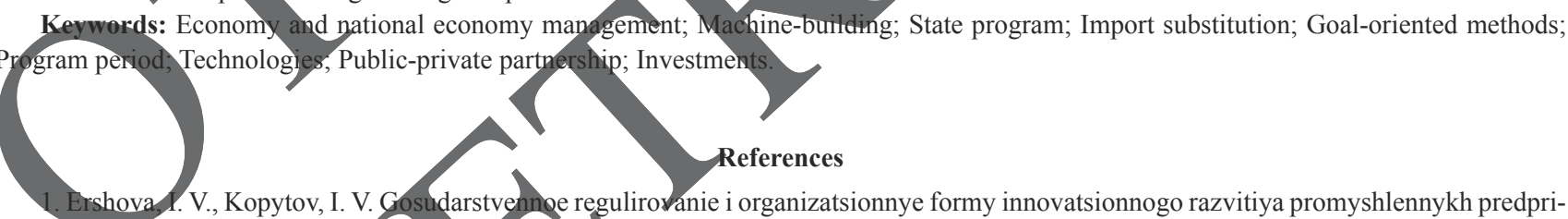
yatii (State regulation an dorganizational form of innovative development of industrial potential of an industrial enterprises), Voprosy upravleniya, 2010, No. 11, pp. 48-53 (in Rus

2. Karsuntseva, O. V ormirovanie i realizatsya strategii povysheniya urovnya ispol'zovaniya proizvodstvennogo potentsiala predpriyatii mashinostroeniya: dis.... d-xa ekon. nauk (Fonning and implementation of strategy of increasing the level of production potential of machinebuilding enterprises: doctoral (Economics) thesis), Samara, 2015, 362 p. (in Russ.)

3. Karsuntseva, O. V. Protsess vosproizvodstva proizvodstvennogo potentsiala promyshlennogo predpriyatiya (Process of reproduction of production potential of an industrial enterprise), Problemy ekonomiki i menedzhmenta, 2013, No. 1 (17), pp. 34-40 (in Russ.).

4. Zhabin, A. P., Volkodavova,E. V., Goryacheva, T. V. Multilevel industrial policy: methodological basis of system approach to its formation and implementation, Asian Social Science, 2015, No. 7, pp. 176-182.

5. Karsuntseva, O. V. Proizvodstvennyi potentsial predpriyatii mashinostroeniya: otsenka, dinamika, rezervy povysheniya (Production potential of machine-building enterprises: estimation, dynamics, reserves of increasing), Moscow: INFRA-M, 2014, 214 p. (in Russ.).

6. Venables, A. J. Trade policy, cumulative causation, and industrial development, Journal of Development Economics, 1996, No. 49, pp. 179-198.

7. Zhabin, A. P., Grabozdin, Yu. P. Rol' i znachenie ispol'zovaniya marketingovykh instrumentov v sfere konsul'tatsionnykh uslug (Role and significance of using the marketing tools in the sphere of consultation services), Vestnik Samarskogo munitsipal'nogo instituta upravleniya, 2014, No. 2 (29), pp. $42-49$ (in Russ.).

8. Davenport, T. H., Beck, J. C. The strategy and structure of firms in the attention economy, Ivey business journal, 2002, No. 4, pp. 48-53.

9. Grabozdin, Yu. P. Organizatsiya informatsionnogo soprovozhdeniya v deyatel'nosti konsul'tatsionnykh kompanii (Organization of informative support in the activity of consultation companies), Ekonomicheskie nauki: teoreticheskii i prakticheskii: sb. st. Mezhdun. nauch.-prakt. 
konferentsii, Ufa: OOO "Aeterna", 2014, pp. 11-14 (in Russ.).

10. Tatarskikh, B. Ya. Strategicheskoe razvitie promyshlennykh predpriyatii na innovatsionnoi osnove (Strategic development of industrial enterprises on innovative basis), Vektor nauki Tol'yattinskogo gosudarstvennogo universiteta, 2011, No. 4, pp. $327-330$ (in Russ.).

11. Karsuntseva, O. V. Organizatsionno-ekonomicheskaya model' povysheniya effektivnosti proizvodstvenno-khozyaistvennoi deyatel'nosti predpriyatiya (Organization-economic model of increasing the efficiency of the production-economic activity of an enterprise), Vektor nauki Tol'yattinskogo gosudarstvennogo universiteta, 2014, No. 1 (27), pp. 122-126 (in Russ.).

12. Tatarskikh, B. Ya. Strategicheskie napravleniya povysheniya effektivnosti mashinostroitel'nogo kompleksa Rossii (Strategic directions of increasing the efficiency of the Russian machine-building complex), Vestnik Samarskogo gosudarstvennogo ekonomicheskogo universiteta, 2013, No. 10 (111), pp. 89-94 (in Russ.).

13. Sekerin, V. D., Dudin, M. N., Lyasnikov, N. V. Genezis innovatsionnykh podkhodov k strategicheskomu razvitiyu sotsial ho-ekonomicheskikh sistem promyshlennogo sektora (Genesis of innovative approaches to strategic development of social-economic systems of industrial sector), Izvestiya Moskovskogo gosudarstvennogo tekhnicheskogo universiteta MAMI, 2014, vol. 5, No. 4 (22), pp. 22-27 (in Russ.).

14. Karsuntseva, O. V. Vyyavlenie i ispol'zovanie rezervov povysheniya proizvodstvennogo potentsiala predpriyatiya (Revealing and using the reserves of increasing the production potential of an enterprise), Intellekt. Innovatsii. Investitsii, 2013 , 0.4 , pp 65-70 (in Russ.).

145 Kozhevnikova, S. A. Razvitie innovatsionno-investitsionnoi deyatel'nosti v toplivno-energeticheskom komplekse: dis. kand. ekon. nauk (Development of innovative-investment activity in fuel-energy complex: PhD (Ecónomics) thesis), Samara,2008, 22 p. (in Russ.

16. Karsuntseva, O. V. Vliyanie innovatsionnogo potentsiala na konkurentosposobnost' promyshlennogo predpriyatiya (Impact of innovative potential on competitiveness of an industrial enterprise), RISK: resursy, informatsiya, snabzhenie, konkurentsiya, 2009, No. 1, p.113-117 (in Russ

17. Toisheva, O. A., Aleksandrova, O. B. Opredelenie klyuchevykh napravlenii gosudarstvennoi podderzhki malogo i srednego predprinimatel'stv v Rossii (Defining the key directions of state support of small and middte-entrepreneurship in Russia), Ekonomika predpxinimatel'stivo, 2015 , No. 3 (56), pp. 936-938 (in Russ.).

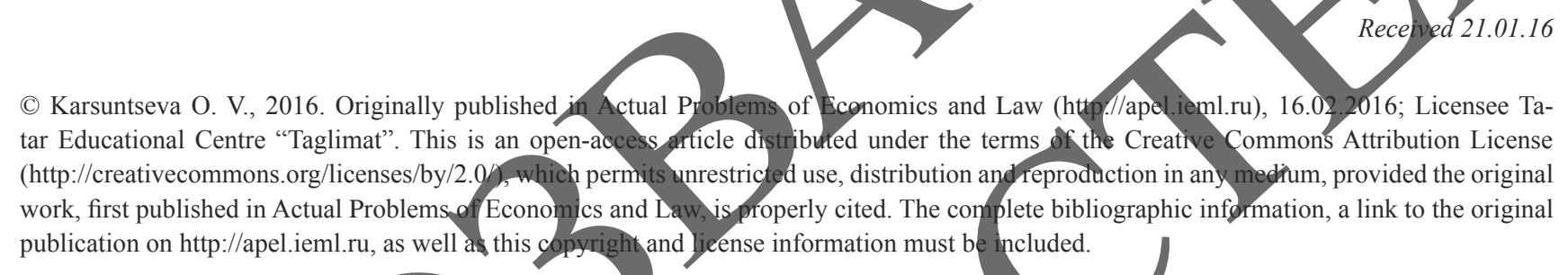
publication on http://apel.ieml.ru, as well a this copyright and lieense information must be included.

Olga V. Karsuntseva, Doctor of Economi Address: 244 Molodogvardeyskaya Str., E-mail: olja989@bk.ru ORCID: http://orcidorg/ 0000-0001-8633-4375 Researcher ID: K-3782-2014 (http://www.researcherid.com)

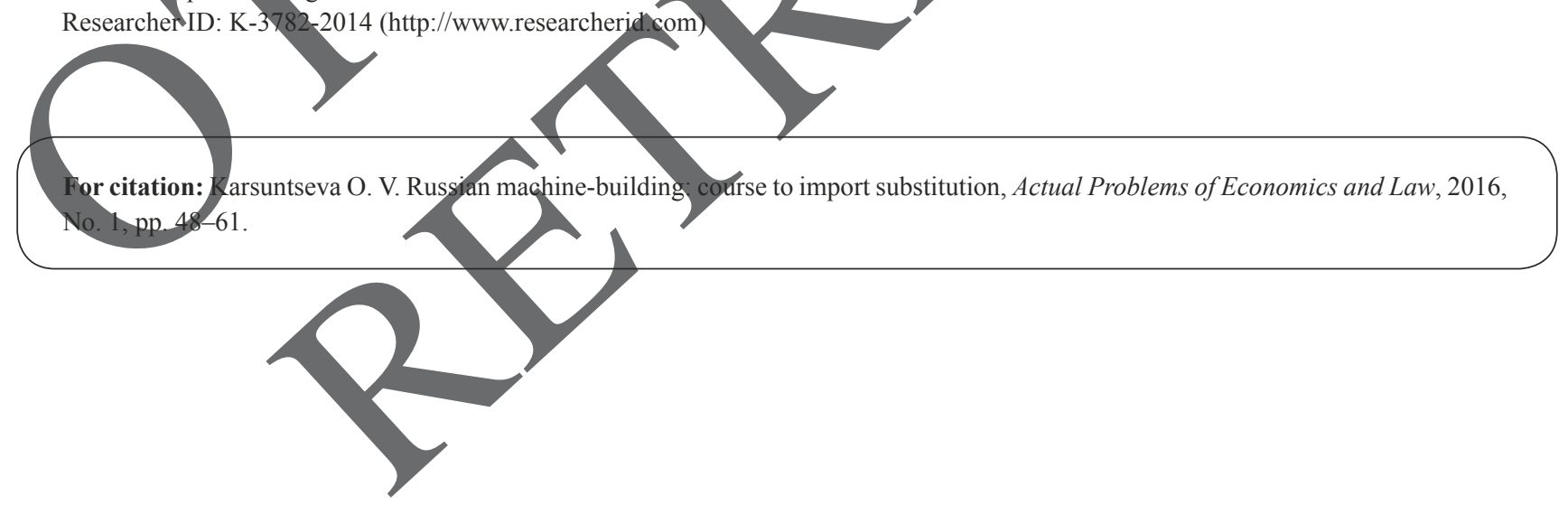

